\title{
Fullerene Active Layers for N-Type Organic Electrochemical Transistors
}

C. G. Bischak†, L. Q. Flagg†, K. Yan†, C. Z. Lił, D. S. Ginger†*

$\dagger$ Department of Chemistry, University of Washington, Seattle, Washington 98195-1700, United States

\$MOE Key Laboratory of Macromolecular Synthesis and Functionalization, State Key Laboratory of Silicon Materials, Department of Polymer Science and Engineering, Zhejiang University, Hangzhou 310027, P.R. China

\section{TABLE OF CONTENTS:}

1. Materials and Methods

2. Supporting Figures S1-S18

3. References 


\section{Materials and Methods}

Synthesis of C60-TEG.
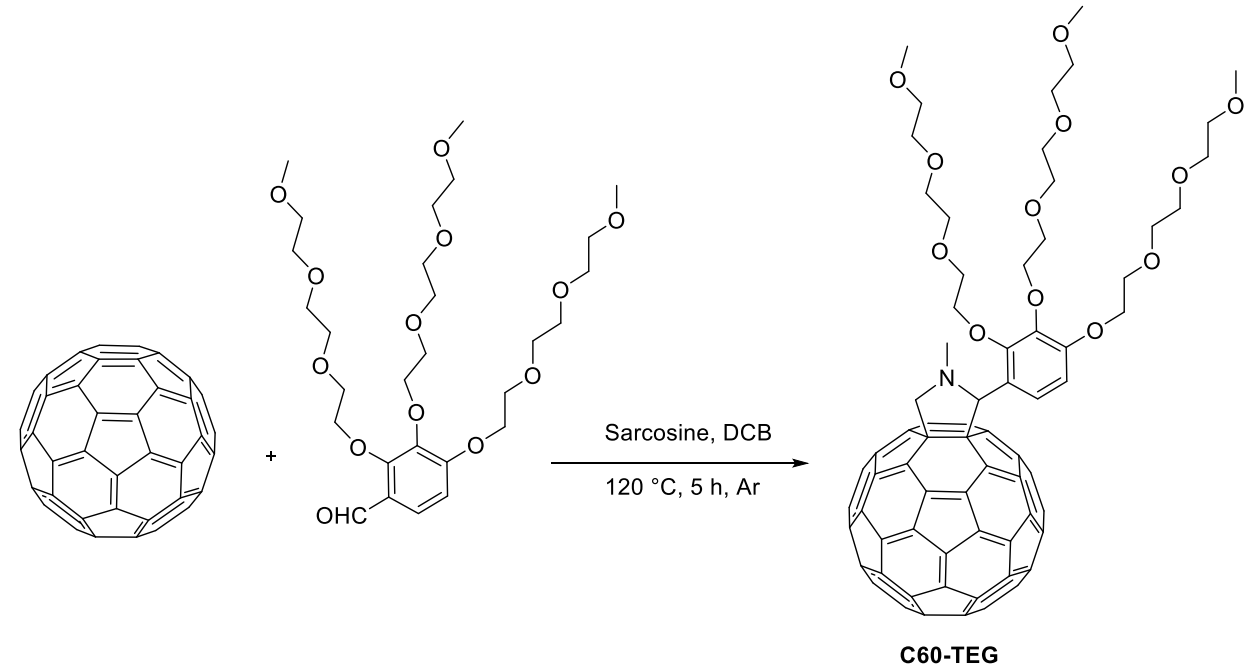

2-(2,3,4-tris(methoxtriglycol) phenyl) [60]fulleropyrrolidine (C60-TEG).

2,3,4-tris(methoxtriglycol)benzaldehyde $377 \mathrm{mg}(0.636 \mathrm{mmol}, 0.8 \mathrm{eq})$, fullerene $\mathrm{C}_{60} 572 \mathrm{mg}$ $(0.795 \mathrm{mmol}, 1 \mathrm{eq})$, and sarcosine $106 \mathrm{mg}(1.19 \mathrm{mmol}, 1.5 \mathrm{eq})$ were dissolved in $30 \mathrm{ml}$ dichlorobenzene (DCB). After bubbled with argon gas for 30 minutes, the reaction mixture was heated to $120{ }^{\circ} \mathrm{C}$ for 5 hours. After cooling to room temperature, the reaction mixture was poured into a silica gel column. Elution with toluene first gave unchanged $\mathrm{C}_{60}$, and then with ethyl acetate: methanol (10:1, v:v) to obtain C60-TEG $230 \mathrm{mg}$ (0.172 mmol, 27\% yield). ${ }^{1} \mathrm{H}$ NMR (400 MHz, $\left.\mathrm{CDCl}_{3}\right) \delta 7.63(\mathrm{~d}, J=8.6 \mathrm{~Hz}, 1 \mathrm{H}, \operatorname{Ar}-\underline{H}), 6.78(\mathrm{~d}, J=8.8 \mathrm{~Hz}, 1 \mathrm{H}, \operatorname{Ar}-\underline{H}), 5.55\left(\mathrm{~s}, 1 \mathrm{H}, \mathrm{NC} \underline{H}_{2}\right), 4.95$ $\left(\mathrm{d}, J=9.2 \mathrm{~Hz}, 1 \mathrm{H}, \mathrm{NC} \underline{H}_{2}\right), 4.35(\mathrm{~s}, 1 \mathrm{H}, \mathrm{NC} \underline{H}), 4.32-4.27\left(\mathrm{~m}, 2 \mathrm{H}, \mathrm{OC} \underline{H}_{2}\right), 4.20-4.12(\mathrm{~m}, 2 \mathrm{H}$, $\left.\mathrm{OC} \underline{H}_{2}\right), 4.11-4.02\left(\mathrm{~m}, 2 \mathrm{H}, \mathrm{OC} \underline{H}_{2}\right), 3.87-3.84\left(\mathrm{~m}, 2 \mathrm{H}, \mathrm{OC} \underline{H}_{2}\right), 3.79-3.77\left(\mathrm{~m}, 6 \mathrm{H}, \mathrm{OC} \underline{H}_{2}\right), 3.73$ $-3.69\left(\mathrm{~m}, 4 \mathrm{H}, \mathrm{OC}_{\underline{H}}\right), 3.67-3.61\left(\mathrm{~m}, 7 \mathrm{H}, \mathrm{OC} \underline{H}_{2}\right), 3.61-3.56\left(\mathrm{~m}, 7 \mathrm{H}, \mathrm{OC} \underline{H}_{2}\right), 3.55-3.50(\mathrm{~m}$, $\left.4 \mathrm{H}, \mathrm{OC} \underline{H}_{2}\right), 3.38\left(\mathrm{~s}, 3 \mathrm{H}, \mathrm{OC} \underline{H}_{3}\right), 3.36\left(\mathrm{~s}, 3 \mathrm{H}, \mathrm{OC} \underline{H}_{3}\right), 3.35$ (s, 3H, OC$\left.\underline{H}_{3}\right), 2.78\left(\mathrm{~s}, 3 \mathrm{H}, \mathrm{NC}_{3}\right) .{ }^{13} \mathrm{C}$ NMR $\left(100 \mathrm{MHz}, \mathrm{CDCl}_{3}\right) \delta 156.82,155.13,154.28,154.13,152.45,152.15,147.30,146.91$, $146.73,146.25,146.20,146.12,146.08,145.94,145.75,145.56,145.54,145.31,145.30,145.25$, $145.23,145.20,145.13,145.11,144.61,144.59,144.43,144.36,143.09,143.00,142.65,142.63$, $142.56,142.54,142.27,142.25,142.15,142.10,142.07,141.99,141.88,141.67,141.56,141.11$, $140.14,140.11,139.53,139.46,136.58,136.50,135.99,134.76,124.60,123.24,109.30,77.27$, 76.95, 75.71, 73.14, 72.00, 71.99, 71.92, 70.89, 70.80, 70.68, 70.59, 70.56, 70.52, 70.41, 70.17, 69.81, 69.72, 69.22, 68.29, 59.09, 59.05, 59.03, 39.94. MS (MALDI-TOF): Cal. for $\mathrm{C}_{90} \mathrm{H}_{53} \mathrm{NO}_{12}$, 1339.36, Found: 1339.83.

OECT device fabrication and measurement. OECT substrates were fabricated, as previously described, ${ }^{1}$ with standard photolithography procedures on polyethyelene terephthalate (PET) substrates by Nano Terra Inc. and contain seven transistors with a length of $20 \mu \mathrm{m}$ and widths between 50 and $4000 \mu \mathrm{m}$ and two gold pads for electrochemical impedance spectroscopy (EIS) measurements $\left(0.0036 \mathrm{~cm}^{2}\right)$. C60-TEG and phenyl-C61-butyric acid methyl ester (PCBM) (Solenne B.V.) were deposited from $10 \mathrm{mg} / \mathrm{ml}$ solutions in anhydrous chloroform (Aldrich) by 
spin coating onto the OECT substrates with thicknesses ranging from 60 to $150 \mathrm{~nm}$ and annealed at $120{ }^{\circ} \mathrm{C}$ for 20 minutes under $\mathrm{N}_{2}$. The fullerene layers were removed from the substrate except for at the electrode junctions and the electrodes were insulated with a nitrocellulose layer (Sally Hansen, Insta-Dri Top Coat). Transfer curves were measured in degassed $100 \mathrm{mM} \mathrm{KCl}$ with an $\mathrm{Ag} / \mathrm{AgCl}$ gate electrode (eDAQ) using two Keithley source measure units and custom Labview software sweeping the gate voltage $\left(V_{G}\right)$ from 0 to $0.8 \mathrm{~V}$ with a constant source-drain voltage $\left(V_{D S}\right.$ $=0.6 \mathrm{~V}$ ) with a step size of $0.01 \mathrm{~V}$ with a $3 \mathrm{~s}$ dwell time between steps. Output curves were also measured on the same setup and same step size and dwell time, sweeping $V_{D S}$ from 0 to $0.7 \mathrm{~V}$ at fixed $V_{G}$. The threshold voltage $\left(V_{t h}\right)$ was calculated by determining the x-intercept of a linear fit of $\operatorname{sqrt}\left(I_{D S}\right)$ vs. $V_{G}$. Stability measurements were performed using a function generator (Agilent 33210A $10 \mathrm{MHz}$ Function/Arbitrary Waveform Generator) to modulate the $V_{G}$ between 0 and 0.5 V (vs. $\mathrm{Ag} / \mathrm{AgCl})$.

Electrochemical measurements. All electrochemical measurements were performed with a Metrohm Autolab PGSTAT204 with NOVA Software (2.1). A Pt wire was used as the counter electrode (Aldrich) and an $\mathrm{Ag} / \mathrm{AgCl}$ electrode (eDAQ) was used as the reference electrode for all measurements. Cyclic voltammetry was acquired in the range of -0.8 to $0.3 \mathrm{~V}(\mathrm{vs}$. $\mathrm{Ag} / \mathrm{AgCl})$ at a rate of $0.1 \mathrm{~V} / \mathrm{s}$.

Spectroelectrochemistry of doping and dedoping kinetics. UV-Vis spectra for spectroelectrochemistry measurements were acquired with an Agilent 8453 spectrometer. PCBM and C60-TEG (100-150 nm) were spin coated onto glass coated with fluorine-doped tin oxide (FTO) substrates (Aldrich). A series of spectra were acquired through the NOVA Software during doping and dedoping in degassed $100 \mathrm{mM} \mathrm{KCl}$ at a range of 0 to $-0.8 \mathrm{~V}$ vs. $\mathrm{Ag} / \mathrm{AgCl}$ for $100 \mathrm{~s}$ once the bias was applied with $100 \mathrm{~ms} / \mathrm{spectrum}$ integration time. The increase in absorption was fit to a biexponential growth in Matlab.

Electrochemical impedance spectroscopy (EIS). EIS measurements were performed on goldcoated PET substrates with an area of $0.036 \mathrm{~cm}^{2}$ and a DC offset of $0.8 \mathrm{~V}$ for both PCBM and C60-TEG. Capacitance was determined using $C \sim 1 /(2 \pi f \operatorname{Im}(Z))$, where $f$ is the frequency and $Z$ is the complex impedance, and calculated based on a fit to Randles circuit $R(R \| C)$. Fitting was performed with the Metrohm NOVA software. Volumetric capacitance $\left(C^{*}\right)$ was determined by dividing this capacitance by the volume with film thicknesses determined with AFM.

Electrochemical quartz crystal microbalance (EQCM). Electrogravimetric measurements were performed using a QCM200 (Stanford Research Systems) on $5 \mathrm{MHz}$ gold-coated AT quartz crystals. Measurements were collected with a three-electrode cell with the fullerene-coated crystal face functioning as the working electrode. The change in frequency was converted to a change in mass using the Sauerbrey equation.

X-ray diffraction (XRD). Samples for XRD were spin coated on $100 \mathrm{Si}$ substrates and annealed for $20 \mathrm{~min}$ at $160{ }^{\circ} \mathrm{C}$ in $\mathrm{N}_{2}$. XRD of PCBM and C60-TEG were obtained using a Bruker D8 Discover with a Pilatus $100 \mathrm{~K}$ large-area 2D detector. 2D data was acquired from 2 to $242 \theta$ with a step size of $112 \theta$ and an integration time of $120 \mathrm{~s}$ per step. Line cuts were plotted using polar integration of the 2D maps. 
Contact angle measurements. Contact angle measurements were acquired using a Kruss DSA100L Drop Shape Analyzer. Samples were spin coated on indium tin oxide (ITO) coated glass and annealed for $20 \mathrm{~min}$ at $120^{\circ} \mathrm{C}$ under $\mathrm{N}_{2}$. A $2 \mu \mathrm{L}$ drop of distilled water was deposited on the surface of a PCBM and C60-TEG and the contact angle was measured by fitting an image of the droplet using the instrument software.

Atomic force microscopy (AFM). Samples for AFM were spin coated on indium tin oxide (ITO) coated glass substrates. AFM topography images, thickness measurements, and electrochemical measurements were acquired on an Asylum Research Cypher-ES instrument using MikroMasch tapping mode tips $(\sim 300 \mathrm{kHz}, \sim 2.8 \mathrm{~N} / \mathrm{m}$ ) or Budget Sensors ContGB-G contact mode tips under $\mathrm{N}_{2}$. For dry and hydrated thickness measurements, a section of the thin film was removed with a razor blade and images were acquired over the interface between the film and bare substrate. Hydrated measurements were performed with the tip and sample submerged in degassed $100 \mathrm{mM}$ $\mathrm{KCl}$. For measuring thickness changes upon doping, a bias is applied between the tip and the ITO substrate to drive $\mathrm{K}^{+}$into the film. The $\mathrm{Z}$ Sensor is monitored upon running multiple $\mathrm{CV}$ curves $(0.3$ to $-0.8 \mathrm{~V})$ while maintaining a constant tip deflection to capture changes in film height upon doping.

Grazing incidence wide angle scattering (GIWAXS). GIWAXS measurements were performed on Beamline 7.3.3 at the Advanced Light Source (ALS) at Lawrence Berkeley National Lab using a Pilatus $2 \mathrm{M}$ area detector and an incidence angle of $0.18^{\circ}$ with $30 \mathrm{~s}$ exposure times. Data was processed using Nika and WAXStools ${ }^{2}$ in Igor Pro. 


\section{Supporting Figures}

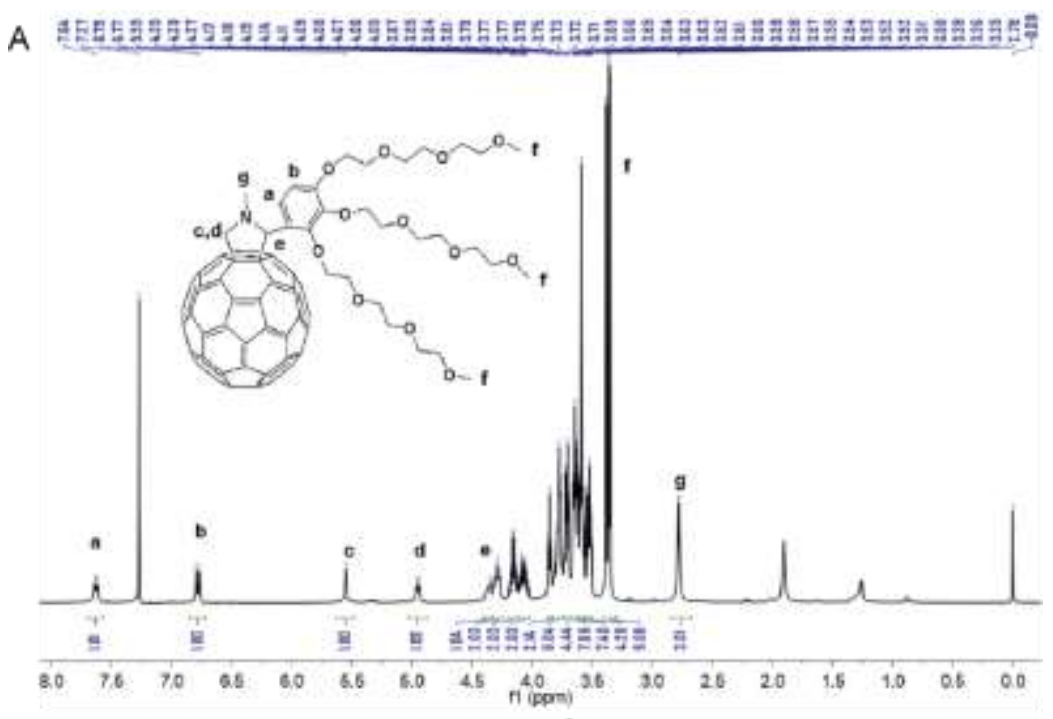

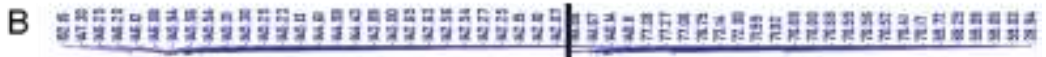
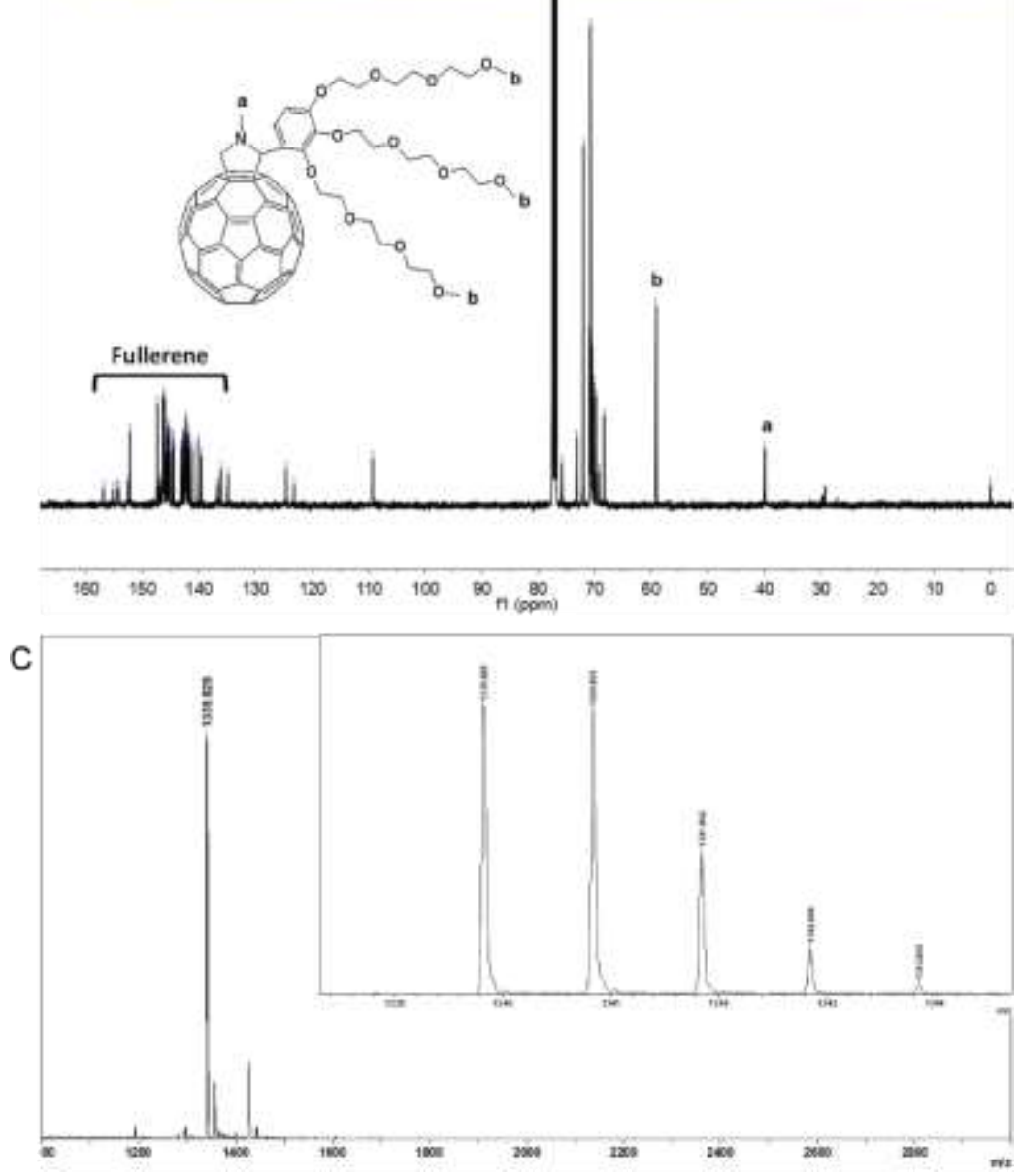

Figure S1. (A) ${ }^{1} \mathrm{H}$ NMR (400M) and (B) ${ }^{13} \mathrm{C}$ NMR (100M) spectra of C60-TEG in $\mathrm{CDCl}_{3}$, and (C) MALDI-TOF mass spectra of C60-TEG. 


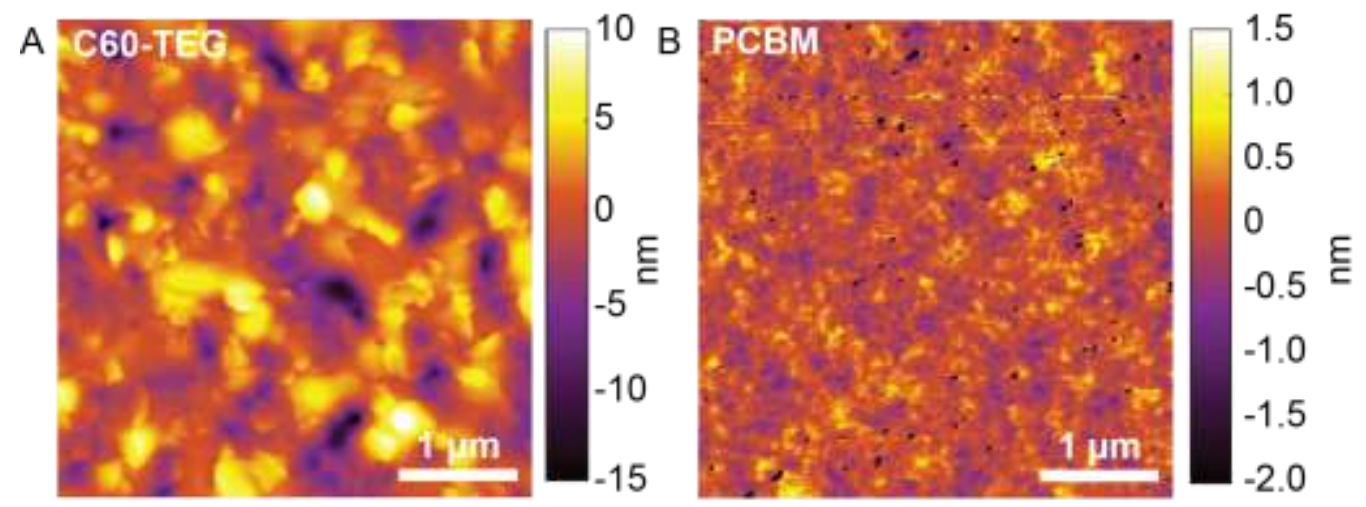

Figure S2: AFM topographies of (A) C60-TEG and (B) PCBM.
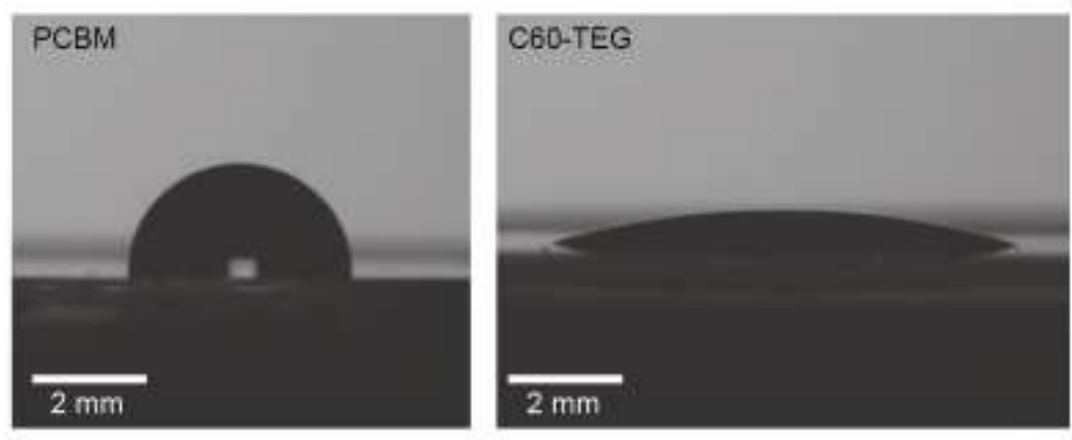

Figure S3: Photographs of water droplets on C60-TEG and PCBM showing the contact angle
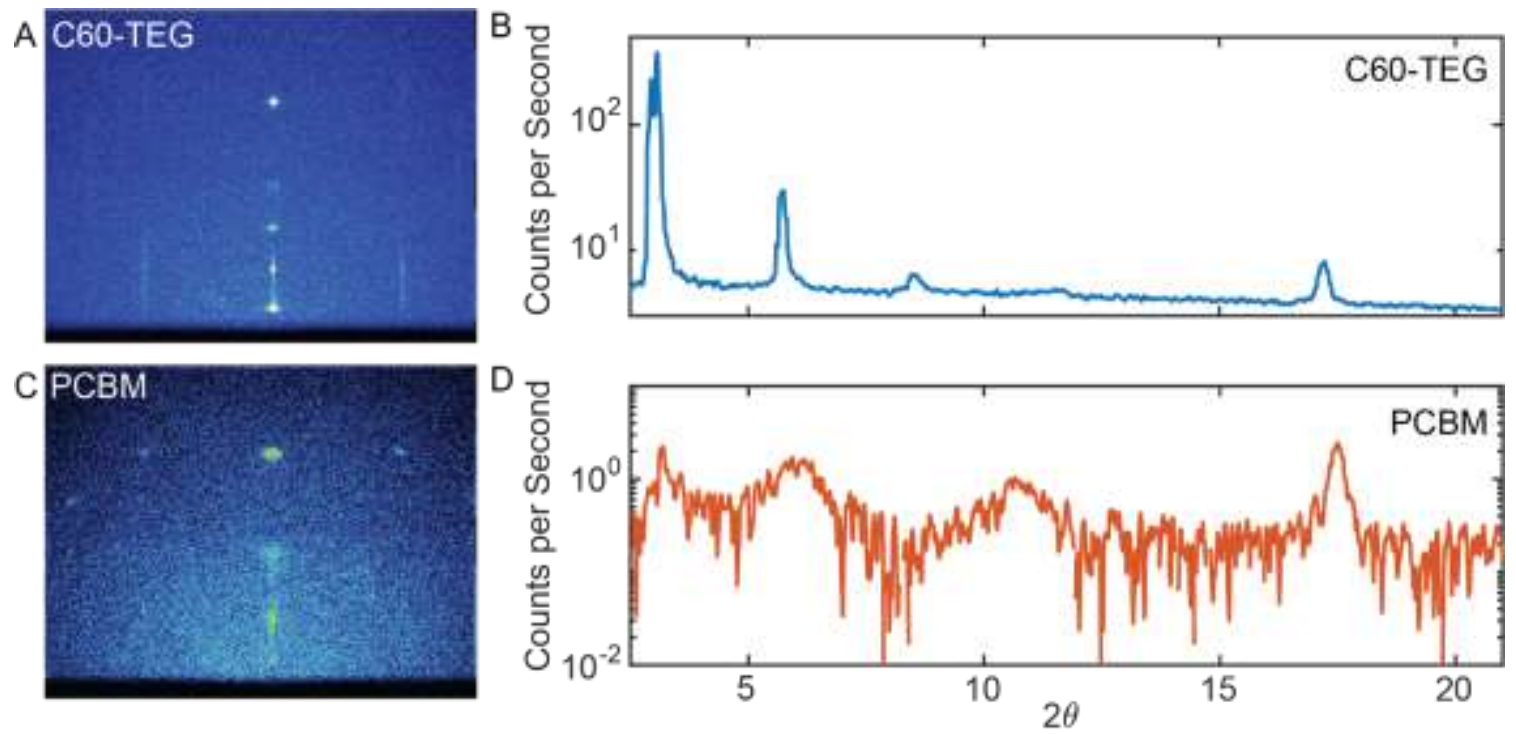

Figure S4: 2D-XRD patterns and associated 1D scans made using polar integration of the 2D scan for (A-B) C60-TEG and (C-D) PCBM. 


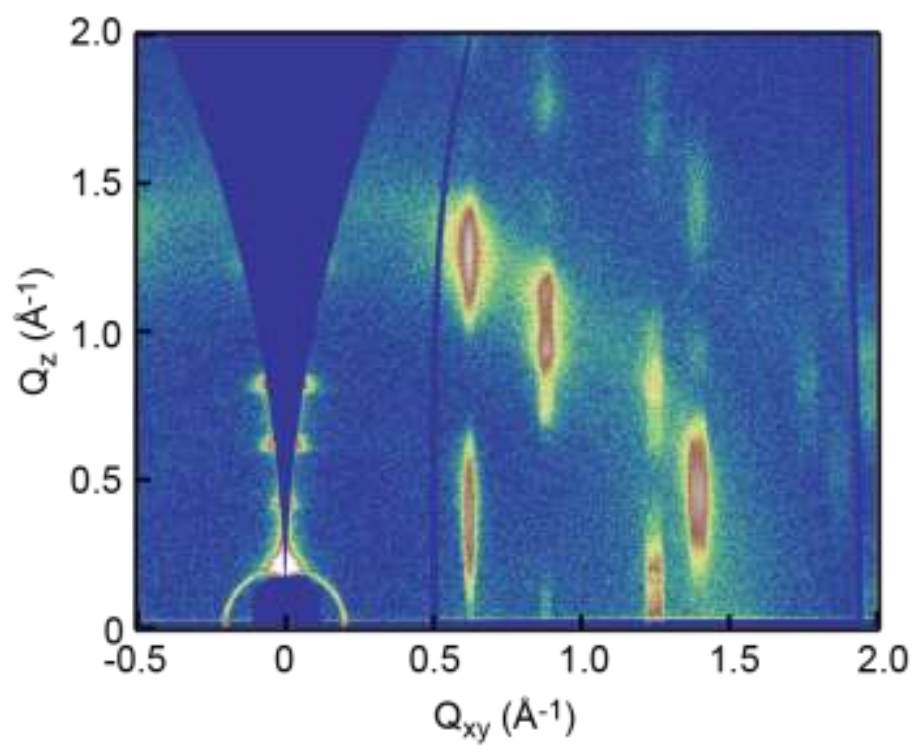

Figure S5: Grazing incidence wide angle scattering (GIWAXS) of C60-TEG.

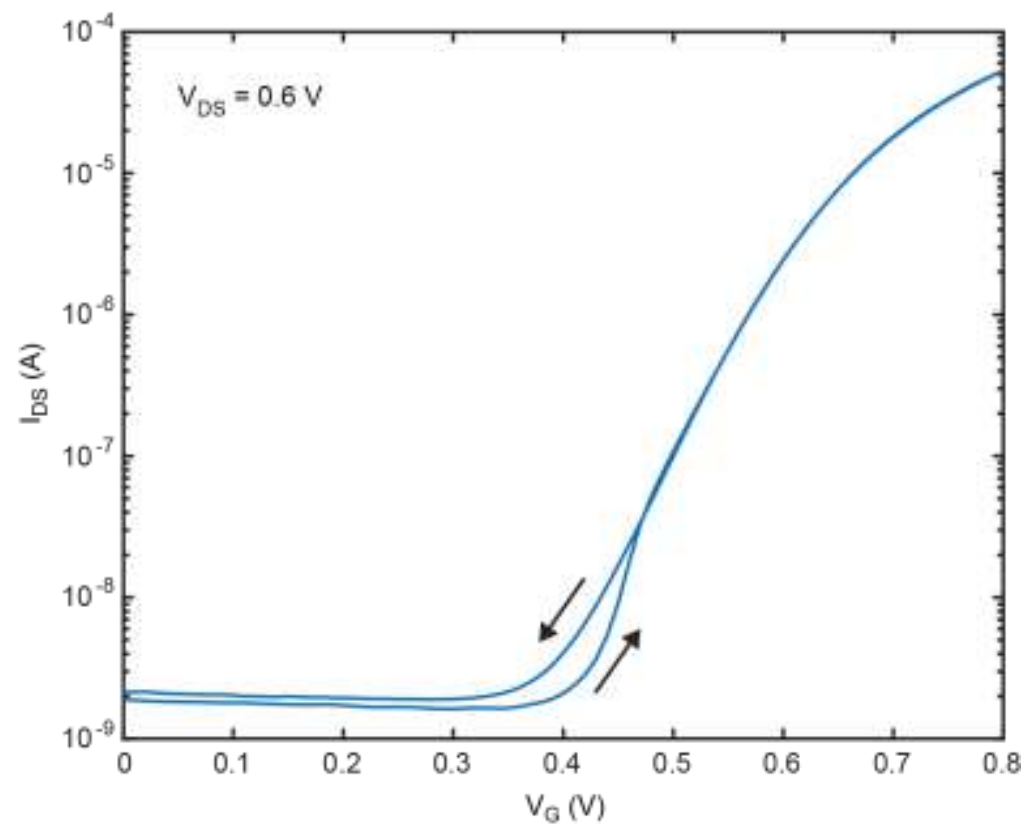

Figure S6: Transfer curve from Figure 1C on a log-linear plot. 


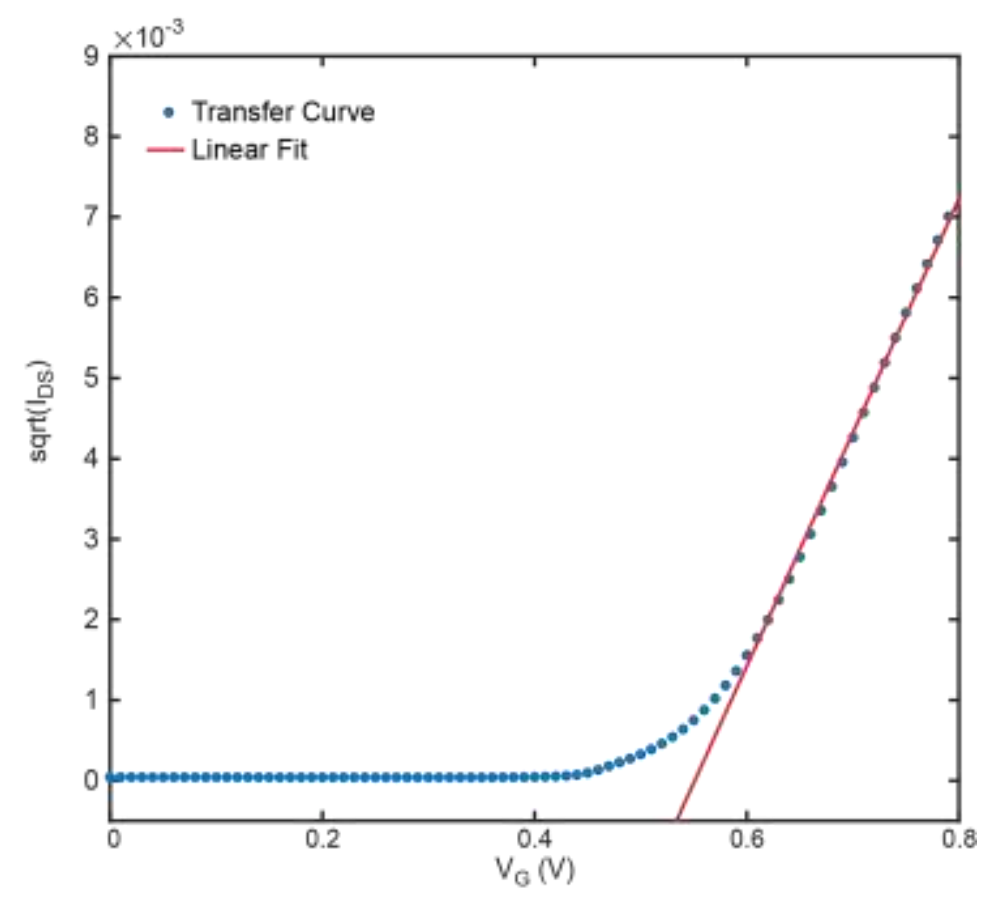

Figure S7: Threshold voltage determination using the linear fit of $\operatorname{sqrt}\left(\mathrm{I}_{\mathrm{DS}}\right)$ vs. $\mathrm{V}_{\mathrm{G}}$.

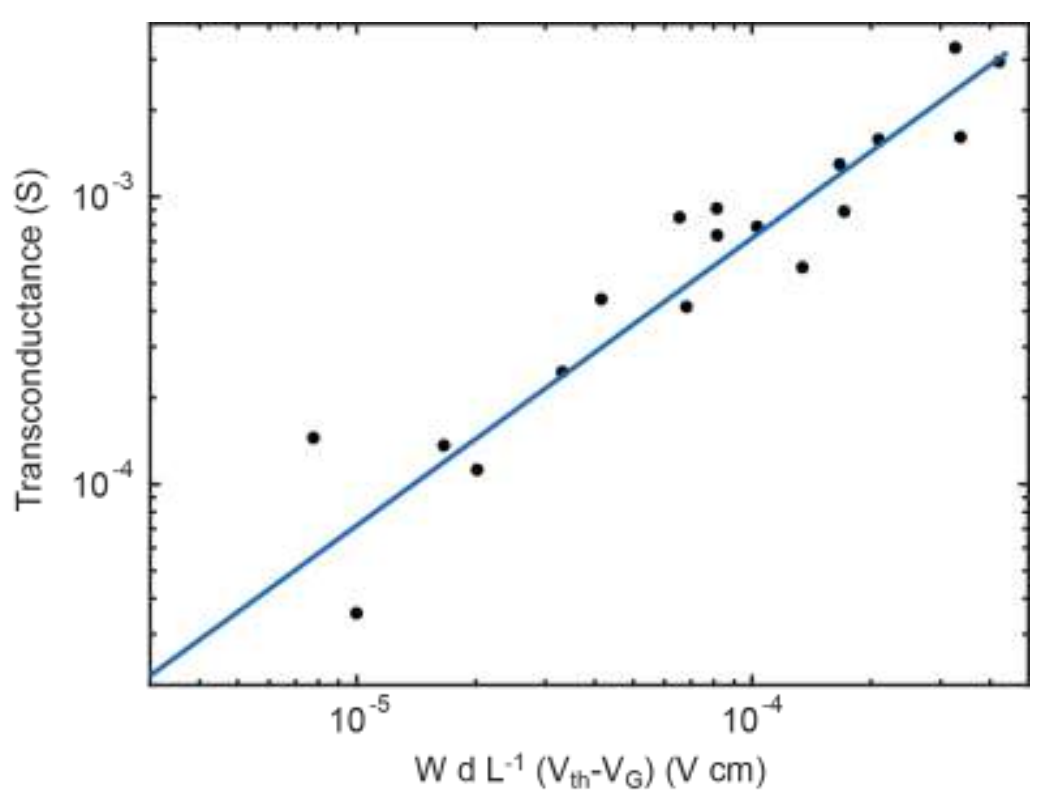

Figure S8: Plot of transconductance $\left(g_{m}\right)$ versus $W d L^{-1}\left(V_{t h}-V_{G}\right)$ for various transistor dimensions and thicknesses ranging from 60 to $150 \mathrm{~nm}$ with a linear fit. The slope of the linear fit is the $\mu C^{*}$. 

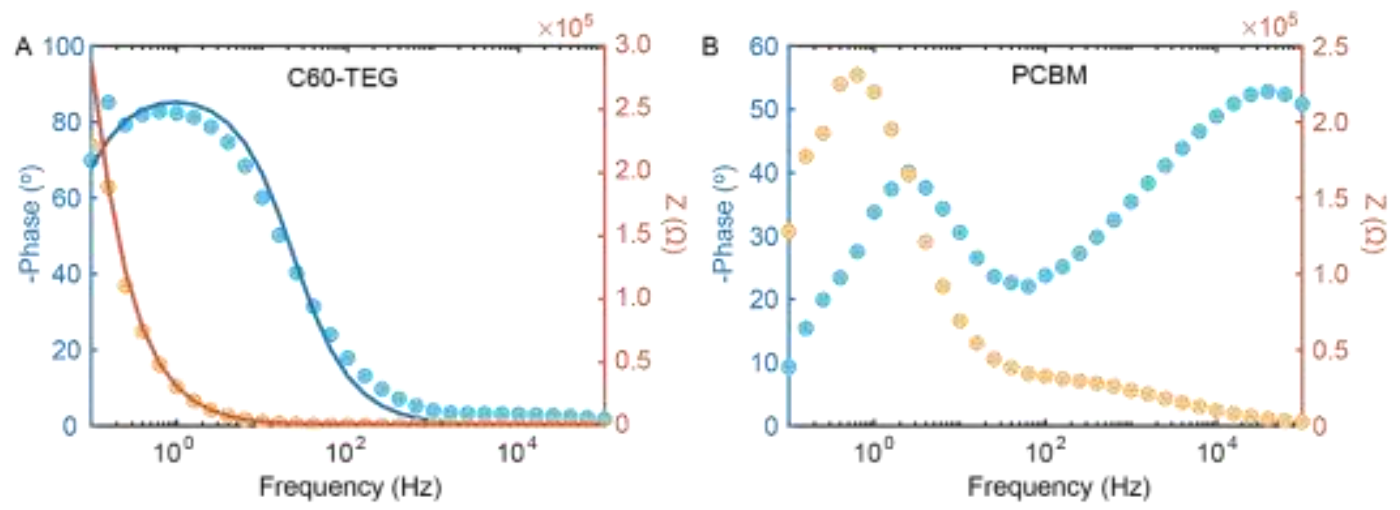

Figure S9: Bode plots of (A) C60-TEG and (B) PCBM at a DC offset of $-0.8 \mathrm{~V}$ (vs. $\mathrm{Ag} / \mathrm{AgCl}$ ) with fits to Randles circuit for C60-TEG. The Bode plot of PCBM closely matches that of a hydrophobic polymer and a gold pad, demonstrating electric double layer capacitance. ${ }^{3}$

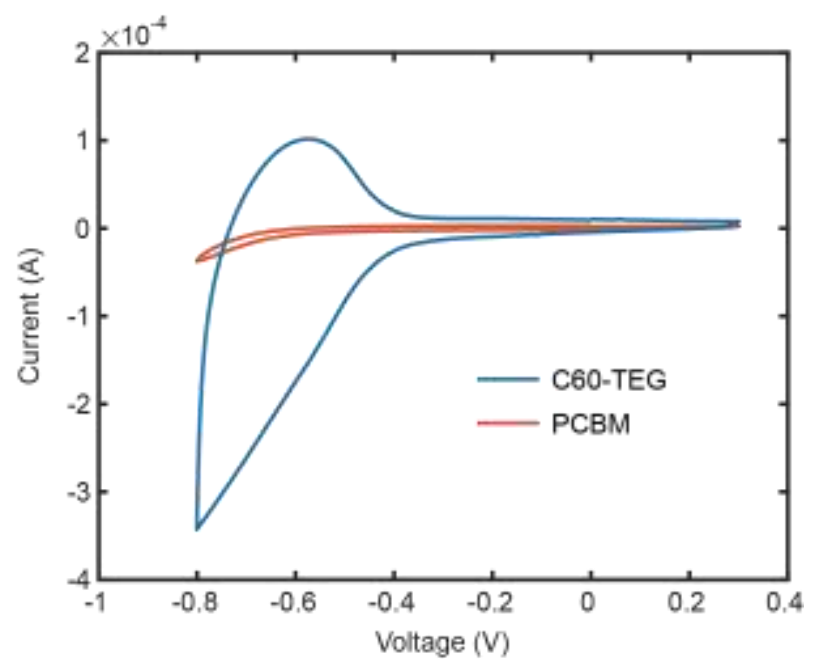

Figure S10: Cyclic voltammetry (CV) of C60-TEG and PCBM at $0.1 \mathrm{~V} / \mathrm{s}$ spanning -0.8 to $0.3 \mathrm{~V}$ (vs. $\mathrm{Ag} / \mathrm{AgCl}$ ). $\mathrm{CV}$ data for $\mathrm{C} 60$-TEG matches similar fullerene derivatives with glycolated side chains. $^{4}$ 

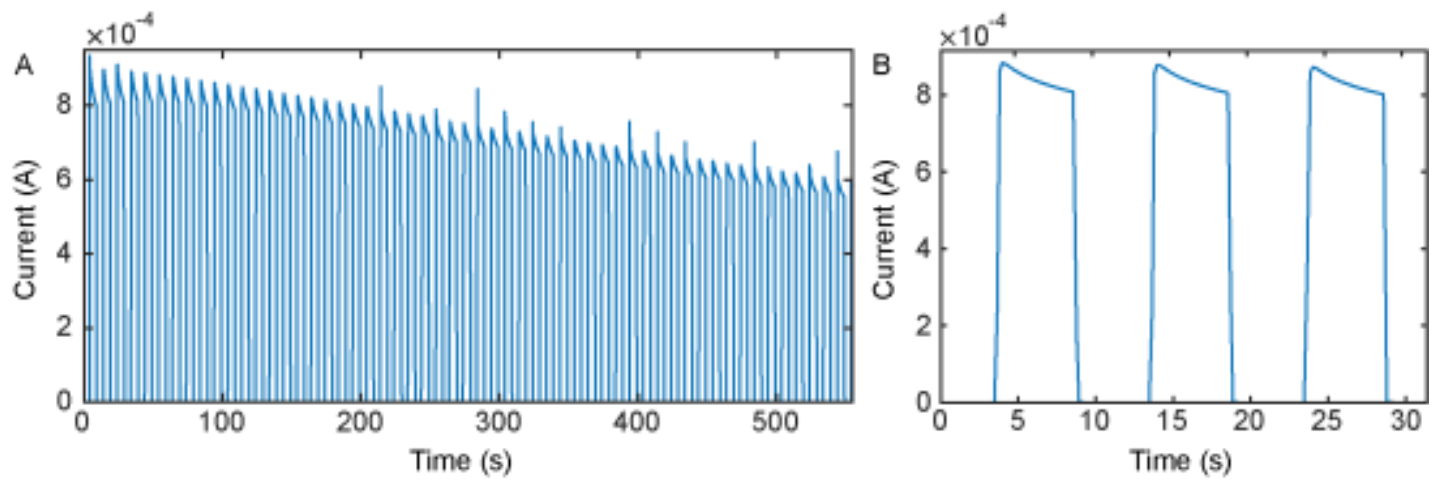

Figure S11: (A) Repeated cycling of a C60-TEG transistor between $\mathrm{V}_{\mathrm{G}}=0$ and $0.5 \mathrm{~V}$ with a $10 \mathrm{~s}$ period. (B) Zoomed in plot of three ON/OFF cycles.
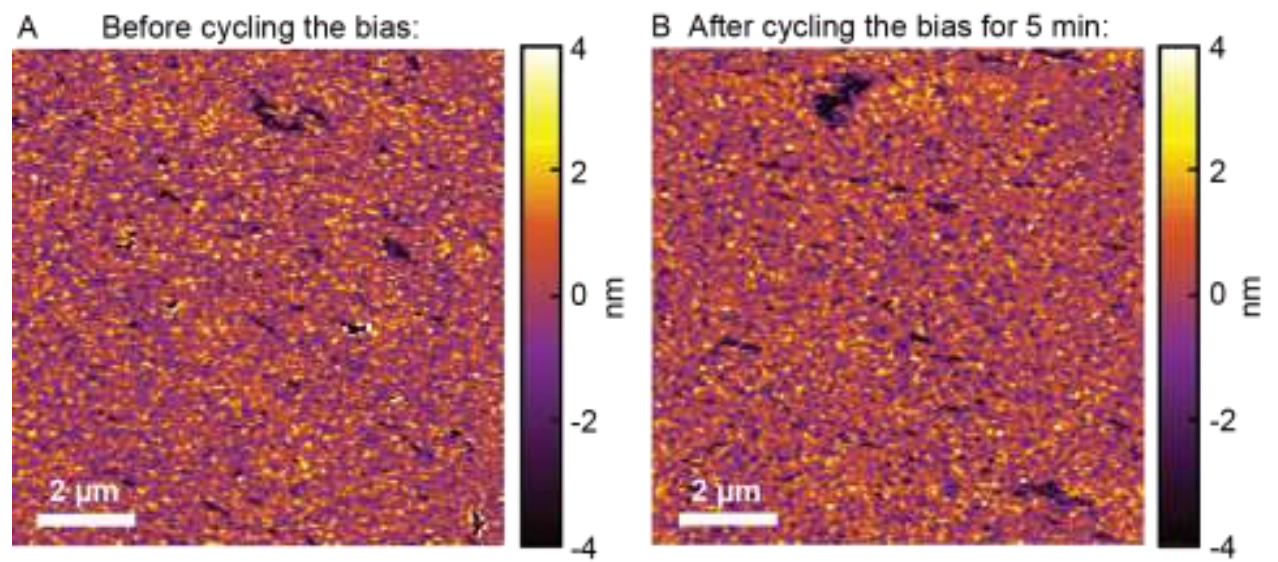

Figure S12: AFM images of C60-TEG thin films (A) before and (B) after 5 min of repeated doping/dedoping cycles. The root mean square (RMS) roughness does not change significantly upon repeated doping/dedoping cycles (1.21 nm RMS to $1.15 \mathrm{~nm}$ RMS)
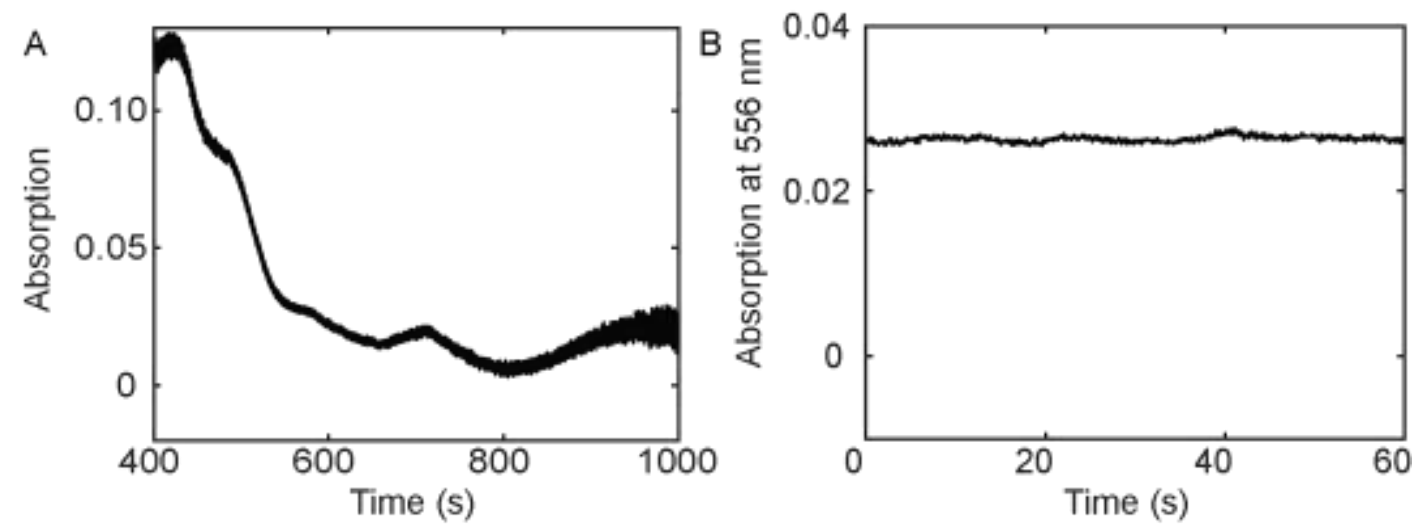

Figure S13: (A) Overlaid absorption spectra of PCBM upon applying a $-0.8 \mathrm{~V}$ (vs. $\mathrm{Ag} / \mathrm{Ag} / \mathrm{Cl}$ ) bias. (B) Change in absorption at $556 \mathrm{~nm}$ as a function of time. 

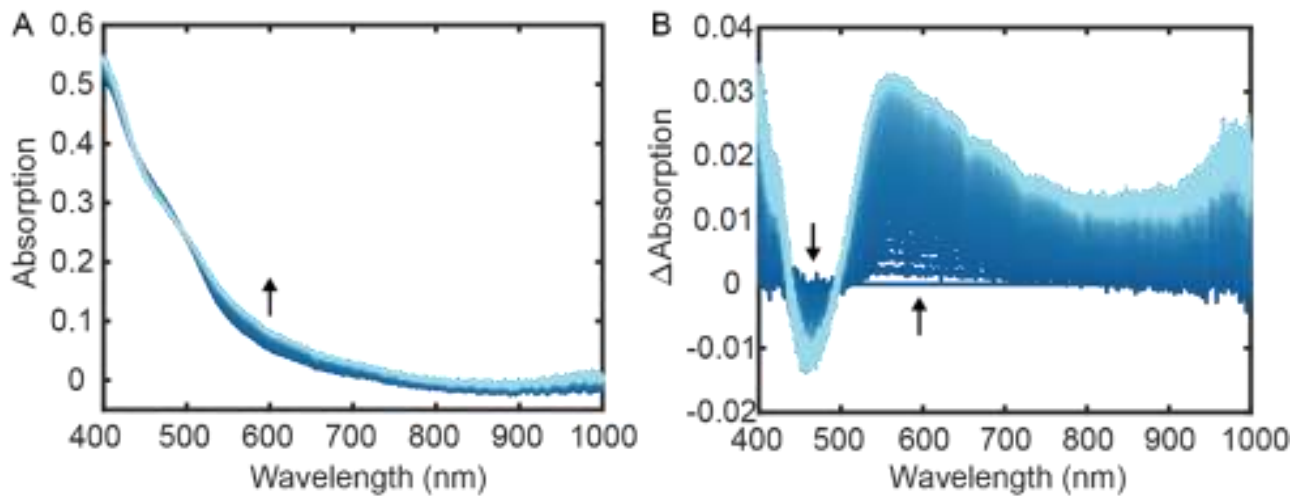

Figure S14: Changes in the absorption spectrum of C60-TEG upon applying a doping bias (-0.8 $\mathrm{V}$ vs. $\mathrm{Ag} / \mathrm{AgCl}$ ) with $0.1 \mathrm{~s}$ integration time per spectrum.
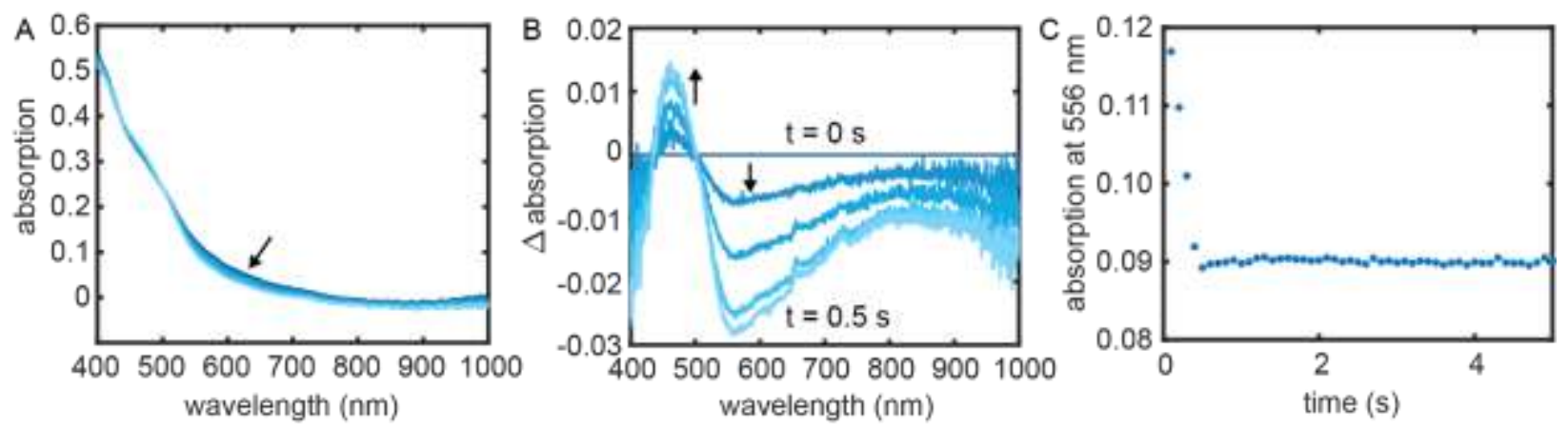

Figure S15: (A) Absorption spectrum of C60-TEG upon dedoping (-0.8 V to $0 \mathrm{~V}$ vs. $\mathrm{Ag} / \mathrm{AgCl})$. (B) Change in the absorption spectrum upon dedoping. (C) Kinetics of dedoping monitored at $556 \mathrm{~nm}$.
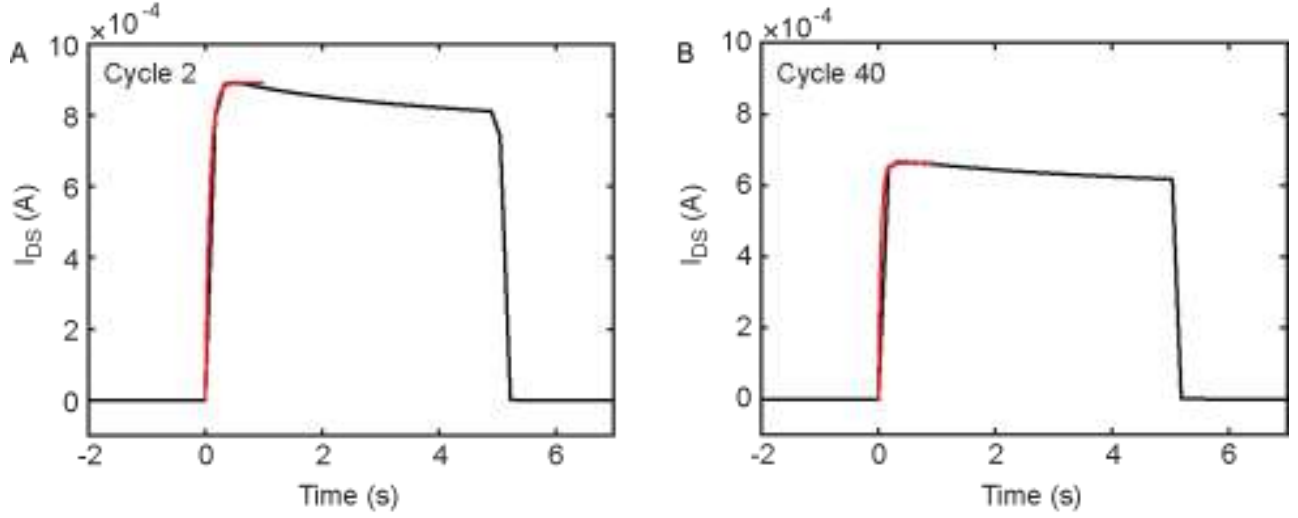

Figure S16: (A) $2^{\text {nd }}$ and (B) $40^{\text {th }}$ cycles of turning $V_{G}$ on and off for $5 \mathrm{~s}$ with single exponential fits (red) to the doping rate. The single exponential fits have a time constant of $80 \pm 10 \mathrm{~ms}$ for the $2^{\text {nd }}$ cycle and $73 \pm 15 \mathrm{~ms}$ for the $40^{\text {th }}$ cycle. 


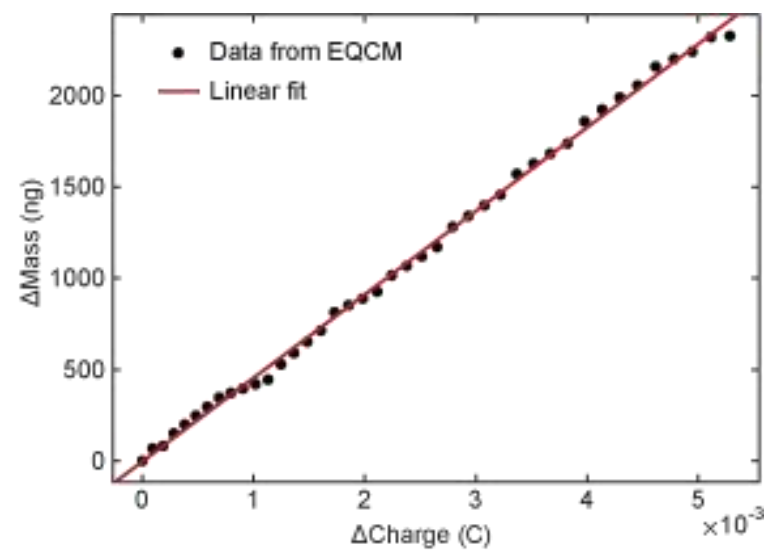

Figure S17: Change in mass versus change in charge at the onset of doping measured with EQCM. The linear fit gives us a molecular weight of $44 \pm 1 \mathrm{~g} / \mathrm{mol}$ per charge. Assuming that the extra mass beyond a single $\mathrm{K}^{+}$is water, we calculate $0.23 \pm 0.3$ waters/ $\mathrm{K}^{+}$or $\sim 2-3$ waters per 10 $\mathrm{K}^{+}$entering the film upon doping.
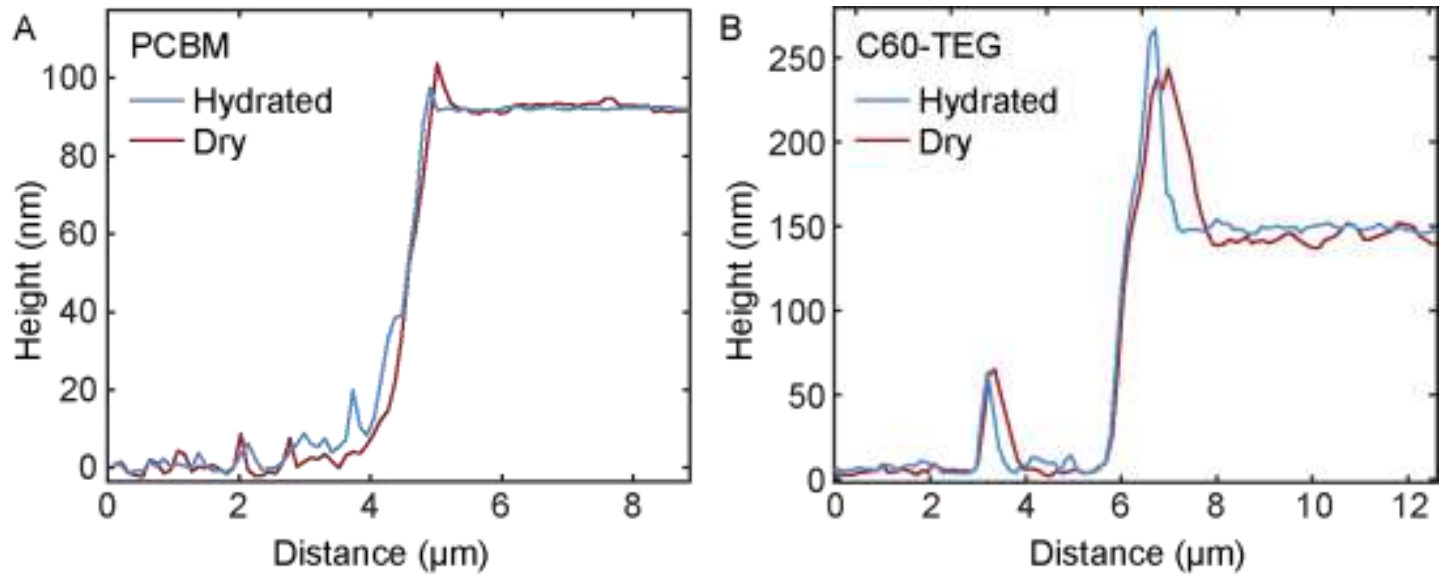

Figure S18: AFM line profiles of (A) PCBM and (B) C60-TEG dry and hydrated in $100 \mathrm{mM}$ $\mathrm{KCl}$. 


\section{Supporting References}

(1) Flagg, L. Q.; Bischak, C. G.; Ginger, D. S. Polymer Crystallinity Controls Water Uptake in Glycol Side Chain Polymer Organic Electro-Chemical Transistors. Journal of the American Chemical Society.

(2) Oosterhout, S. D.; Savikhin, V.; Zhang, J.; Zhang, Y.; Burgers, M. A.; Marder, S. R.; Bazan, G. C.; Toney, M. F. Mixing Behavior in Small Molecule:Fullerene Organic Photovoltaics. Chem. Mater. 2017, 29 (7), 3062-3069. https://doi.org/10.1021/acs.chemmater.7b00067.

(3) Giovannitti, A.; Sbircea, D.-T.; Inal, S.; Nielsen, C. B.; Bandiello, E.; Hanifi, D. A.; Sessolo, M.; Malliaras, G. G.; McCulloch, I.; Rivnay, J. Controlling the Mode of Operation of Organic Transistors through Side-Chain Engineering. Proc. Natl. Acad. Sci. U.S.A. 2016, 113 (43), 12017-12022. https://doi.org/10.1073/pnas.1608780113.

(4) Jahani, F.; Torabi, S.; Chiechi, R. C.; Koster, L. J. A.; Hummelen, J. C. Fullerene Derivatives with Increased Dielectric Constants. Chem. Commun. 2014, 50 (73), 1064510647. https://doi.org/10.1039/C4CC04366A. 